\title{
ROLE OF Y-CHROMOSOME IN MALE CROSSING-OVER IN DROSOPHILA ANANASSAE
}

\author{
DAIGORO MORIWAKI, YOSHIKO N. TOBARI \\ AND MUNEO MATSUDA \\ Department of Biology, Tokyo Metropolitan University, \\ 2-1-1 Fukasawa, Setagaya-ku, Tokyo 158
}

Received May 31, 1979

\begin{abstract}
Genetic factors controlling recombination frequencies in the second and the third chromosomes of males with constructed genomes of autosomes and Y-chromosome from several strains of D. ananassae were investigated. Recombination frequencies were highly variable depending on the genomes of the male. The highest recombination value in the interval of $m l-r u$ on the third chromosome was $42.8 \%$, which was close to the value in the female, $45.4 \%$. The presence of major genetic factors in the autosomes was diagnosed, and some factors in the Y-chromosome were concurrently revealed, especially in that derived from the Tonga "dark" form. It is most worthy of note that highest recombination in the second chromosome was observed in the male constructed of Tonga autosomes, $\mathrm{Y}$ from cosmopolitan form, and $\mathrm{X}$ and cytoplasm from the marker strain.
\end{abstract}

Drosophila ananassae is characterized by considerable frequencies of spontaneous crossing-over in the male (cf. Moriwaki and Tobari 1975). Significant differences in recombination frequencies between reciprocal heterozygous males were found previously (Moriwaki et al. 1970); $\mathrm{F}_{1}$ male from the cross, marker female $\times$ Tonga male, exhibited higher recombination than $F_{1}$ male of the reciprocal cross, Tonga female $\times$ marker male. Therefore effect of the Y-chromosome on male crossing-over was suggested.

The present experiment was carried out to investigate effects of Y-chromosome and other genetic factors, including cytoplasmic ones, on crossing-over in males.

\section{MATERIALS AND METHODS}

D. ananassae has been recorded from all six geographical zones, and it is largely tropical in its distribution, as a "cosmopolitan" form. A "dark" form of its species collected from the South Pacific Island has been distinguished generally by body color from the cosmopolitan form (Futch 1966). Reproductive isolation between them, to some extent, has been found (unpublished).

The following strains of $D$. ananassae were used in Experiments I and II, respec- 
tively:

\section{Experiment $I$}

$\mathrm{T}$ : an inbred line, $\mathrm{T}-15-4$, of Tonga wild type, one of the dark forms. The Tonga stock has been kept in our laboratory since 1965, when it was transferred from the University of Texas at Austin.

$\mathrm{H}$ : an inbred line, $\mathrm{AAg}_{3}$, of Hawaii wild type, one of the cosmopolitan forms. The Hawaii stock has been kept since 1950, when it was transferred from the University of Hawaii.

Q: a tester strain marked with $D l b w ; M(3) d r u . \quad D l$ (Delta wing venation) and $b w$ (brown eye color) are located in the second chromosome with $7.5 \%$ recombination between them in females, whereas $M(3) d$ (Minute bristles) and $r u$ (roughoid eyes) mark the third chromosome with $48.0 \%$ recombination in females.

$\mathrm{M}$ : a strain marked with $b w ; r u$.

\section{Experiment II}

$\mathrm{T}$ : a wild type strain of Tonga, dark form, as in Experiment I.

E: a wild type strain E22 from Calcutta, cosmopolitan form (Moriwaki and Tobari 1973).

L: a wild type strain L8 from Colombo, cosmopolitan form (Moriwaki and Tobari 1973).

$\mathrm{Q}^{\prime}:$ a tester strain marked with $D l b w ; m l r u$, in which $m l$ (minute-like bristles) shows $45.4 \%$ recombination with $r u$ in females.

$\mathrm{M}^{\prime}$ : a strain marked with $b w ; m l r u$.

In Experiment I, the two strains, $\mathrm{T}$ and $\mathrm{H}$, which are characterized by high and low male crossing-over, respectively (Moriwaki et al. 1970), were combined to produce males carrying the $\mathrm{Y}$ and autosomes $(\mathrm{A})$ of either strain, together with the $\mathrm{X}$-chromosome, autosomes and cytoplasm from the marker strain according to the mating schema shown in Fig. 1a and b.

In Experiment II, using the three strains, T, E, and L, each of which is characterized with different degree of male crossing-over $(\mathrm{T}>\mathrm{E}>\mathrm{L}$ ) (Moriwaki et al. 1978), males carrying a genome constructed of Y-chromosome from one strain and autosomes from the same or one of the other two strains, together with the cytoplasm, X-chromosome and autosomes from either a wild strain or the marker strain were obtained to be examined recombination frequencies. The mating schema are shown in Fig. 1c and $\mathrm{d}$.

In both experiments recombination was examined in the structurally homozygous males for the second and the third chromosomes at $25^{\circ} \mathrm{C}$. The heterochromatic chromosome 4 was not marked so that its origin with respect to the parental wild strains was not controlled.

\section{RESULTS}

\section{Experiment $I$.}

The purpose of this experiment is to ascertain the role of the Y-chromosome in 
(a)

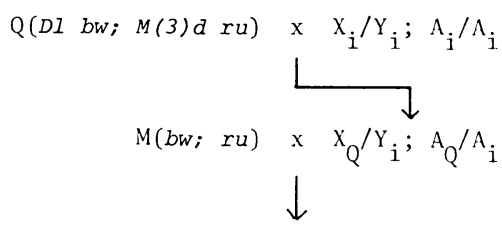

Scored for recombination

(b)

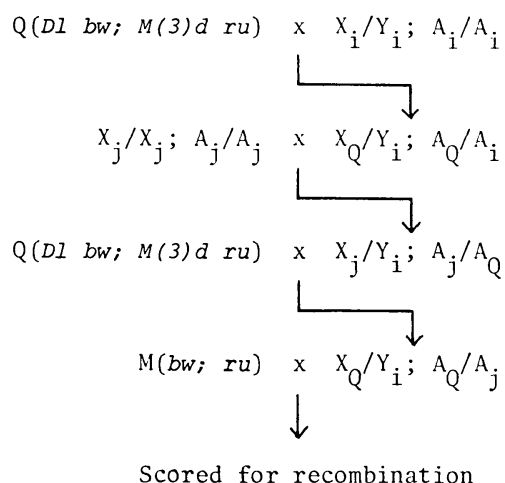

(c)

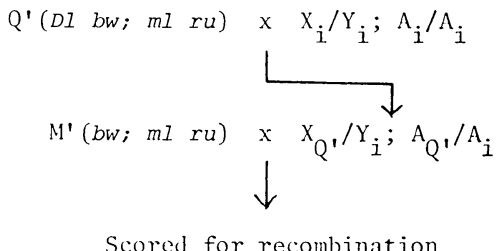

(d)

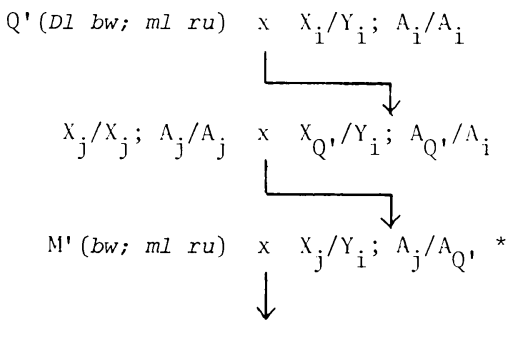

Scored for recombination

Fig. 1. Procedures to produce the male used to examine male recombination: (a) and (b) in the Experiment I, (c) and (d) in the Experiment II. The subscripts $Q, Q^{\prime}, i$ and $\mathrm{j}$ designate the strains from which the chromosomes are derived. $\mathrm{Q}, \mathrm{Q}^{\prime}, \mathrm{M}$ and $\mathrm{M}^{\prime}$ represent the marker females.

* The males of the proper genotype were selected after examination for segregation of $m l$ and $r u$ in their progeny.

male crossing-over, in combination with X-chromosome and cytoplasm originated from the marker stock. According to the combination of Y-chromosome and autosomes (A) of the two strains, $T$ and $H$, the males were classified into four classes (Table 1a), with subscripts $\mathrm{T}$ and $\mathrm{H}$ designating the strain from which the chromosomes were derived. Recombination values for each class are summarized in Table $1 \mathrm{a}$ and the comparisons between classes are presented in Table 1b. Angular transformation was applied to the data to calculate the significances between the classes.

Comparing the male recombination values among the four classes, the effect of Ychromosome can be detected. First of all, it is clear that the recombination values both for $D l$-bw and $M(3) d-r u$ are much higher in $\mathrm{X}_{\mathrm{Q}} / \mathrm{Y}_{\mathrm{T}} ; \mathrm{A}_{\mathrm{Q}} / \mathrm{A}_{\mathrm{T}}$ males than in $\mathrm{X}_{\mathrm{Q}} / \mathrm{Y}_{\mathrm{H}}$; $\mathrm{A}_{\mathrm{Q}} / \mathrm{A}_{\mathrm{H}}$ males. This result is consistent with that previously shown by Moriwaki et al. (1970), that is, the sons from outcrosses of the $T$ strain has a high level of male recombination in contrast to those from the $\mathrm{H}$ strain. Next, the Y-chromosome derived 
Table 1. a: Male recombination values for the intervals $D l-b w$ on the second chromosome and $M(3) d-r u$ on the third chromosome in Experiment I, and b: Comparisons between various two classes

a

\begin{tabular}{ccccccc}
\hline Class & Genotype (Cytoplasm) & $\begin{array}{c}\text { Mating } \\
\text { scheme }\end{array}$ & $\begin{array}{c}\text { Male recombination } \\
\text { value }(\%) \pm \mathrm{S} . \mathrm{E} .\end{array}$ & $\begin{array}{c}\text { No. of } \\
\text { families }\end{array}$ & $\begin{array}{c}\text { No. of } \\
\text { progeny }\end{array}$ \\
\hline$(1)$ & $\mathrm{X}_{\mathrm{Q}} / \mathrm{Y}_{\mathrm{T}} ; \mathrm{A}_{\mathrm{Q}} / \mathrm{A}_{\mathrm{T}}(\mathrm{Q})$ & $\mathrm{a}$ & $0.92 \pm 0.45$ & $27.33 \pm 1.14$ & 10 & 2725 \\
$(2)$ & $\mathrm{X}_{\mathrm{Q}} / \mathrm{Y}_{\mathrm{H}} ; \mathrm{A}_{\mathrm{Q}} / \mathrm{A}_{\mathrm{H}}(\mathrm{Q})$ & $\mathrm{a}$ & $0.08 \pm 0.05$ & $7.76 \pm 1.04$ & 12 & 3852 \\
$(3)$ & $\mathrm{X}_{\mathrm{Q}} / \mathrm{Y}_{\mathrm{T}} ; \mathrm{A}_{\mathrm{Q}} / \mathrm{A}_{\mathrm{H}}(\mathrm{Q})$ & $\mathrm{b}$ & $0.47 \pm 0.26$ & $13.47 \pm 7.87$ & 9 & 1518 \\
$(4)$ & $\mathrm{X}_{\mathrm{Q}} / \mathrm{Y}_{\mathrm{H}} ; \mathrm{A}_{\mathrm{Q}} / \mathrm{A}_{\mathrm{T}}(\mathrm{Q})$ & $\mathrm{b}$ & $3.23 \pm 1.40$ & $26.09 \pm 6.23$ & 5 & 1123 \\
\hline
\end{tabular}

b

\begin{tabular}{ccccccc}
\hline & $(1)-(2)$ & $(1)-(3)$ & $(1)-(4)$ & $(2)-(3)$ & $(2)-(4)$ & $(3)-(4)$ \\
\hline 2-chr. & $>$ & $>$ & $<$ & $<$ & $<$ & $<$ \\
3 -chr. & $0.05>p>0.01$ & $0.5>p>0.4$ & $0.1>p>0.05$ & $0.1>p>0.05$ & $0.01>p$ & $0.01>p$ \\
& $>0.01>p$ & $0.05>p>0.01$ & $0.5>p>0.4$ & $0.6>p>0.5$ & $0.01>p$ & $0.2>p>0.1$ \\
\end{tabular}

from $T$ strain seems to make the value higher than the $Y$ from the $H$ strain, $\left(X_{Q} / Y_{T}\right.$; $\left.A_{Q} / A_{H}>X_{Q} / Y_{H} ; A_{Q} / A_{H}\right)$, though not significant, suggesting a role of $Y$-chromosome in male crossing-over. Thus, existence of some active factors in $\mathrm{Y}$ can be postulated. However, the relation between $X_{Q} / Y_{T} ; A_{Q} / A_{T}$ and $X_{Q} / Y_{T} ; A_{Q} / A_{H}$ shows that the maximum effect of $Y_{T}$ is realized only in combination with $A_{T}$. That the $A_{T}$ contribute to male crossing-over is shown by the highest recombination manifested in the second chromosome, even in the presence of $\mathrm{Y}_{\mathrm{H}}\left(\mathrm{X}_{\mathrm{Q}} / \mathrm{Y}_{\mathrm{H}} ; \mathrm{A}_{\mathrm{Q}} / \mathrm{A}_{\mathrm{T}}\right)$. In other words, in males of "hybrid genome" the higher frequency of recombination was observed. This fact leads to an inference that there may be some interaction between the Y-chromosome and autosomes for male recombination, at least in the second chromosome, which is highest when these elements are derived from different origins.

Moreover, the fact that the values in class (4) $X_{Q} / Y_{H} ; A_{Q} / A_{T}$ are significantly higher than those in class $(2) \mathrm{X}_{\mathrm{Q}} / \mathrm{Y}_{\mathrm{H}} ; \mathrm{A}_{\mathrm{Q}} / \mathrm{A}_{\mathrm{H}}$ in both intervals, also indicates that some factors in the autosomes from the $T$ strain $\left(A_{T}\right)$ have distinct influence on male crossing-over and that more effectively than those from the $\mathrm{H}$ strain $\left(\mathrm{A}_{\mathrm{H}}\right)$.

On the other hand, in the last two classess, $X_{Q} / Y_{T} ; A_{Q} / A_{H}$ and $X_{Q} / Y_{H} ; A_{Q} / A_{T}$, variance for each value was rather large. It would be possible that some recombinant autosomes, instead of the intact ones from the strains in question, were involved in heterozygous males to be examined recombination frequencies, during the process of the chromosome substitution, on account of male crossing-over, somewhat unavoidable owing to the mating scheme as shown in Fig. 1b. Furthermore, since the number of males tested in these classes was small, the variance on random expectation for 4chromosome origin would be large. 
Table 2. a: Male recombination values for the intervals $D l-b w$ on the second chromosome and $m l-r u$ on the third chromosome in Experiment II, and b: Comparisons between various two classes in each group

a

\begin{tabular}{|c|c|c|c|c|c|c|c|}
\hline \multirow{2}{*}{ Group } & \multirow{2}{*}{ Class } & \multirow{2}{*}{ Genotype (Cytoplasm) } & \multirow{2}{*}{$\begin{array}{l}\text { Mating } \\
\text { scheme }\end{array}$} & \multicolumn{2}{|c|}{$\begin{array}{l}\text { Male recombination } \\
\text { value }(\%) \pm S . E .\end{array}$} & \multirow{2}{*}{$\begin{array}{l}\text { No. of } \\
\text { families }\end{array}$} & \multirow{2}{*}{$\begin{array}{l}\text { No. of } \\
\text { progeny }\end{array}$} \\
\hline & & & & $D l-b w(2-\mathrm{chr})$. & $m l-r u$ (3-chr.) & & \\
\hline \multirow[t]{4}{*}{ A } & $(1)$ & $\mathrm{X}_{\mathrm{Q}^{\prime}} / \mathrm{Y}_{\mathrm{T}} ; \mathrm{A}_{\mathrm{Q}^{\prime} / \mathrm{A}_{\mathrm{T}}\left(\mathrm{Q}^{\prime}\right)}$ & $\mathrm{c}$ & $1.82 \pm 0.75$ & $42.78 \pm 1.87$ & 13 & 1002 \\
\hline & $(2)$ & 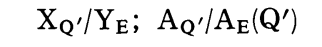 & c & $0.19 \pm 0.09$ & $11.33 \pm 1.25$ & 14 & 1942 \\
\hline & (3) & $\mathrm{X}_{\mathrm{E}} / \mathrm{Y}_{\mathrm{T}} ; \mathrm{A}_{\mathrm{Q}^{\prime}} / \mathrm{A}_{\mathrm{E}}(\mathrm{E})$ & $\mathrm{d}$ & $0.29 \pm 0.17$ & $20.86 \pm 2.56$ & 10 & 1459 \\
\hline & (4) & $\mathrm{X}_{\mathrm{T}} / \mathrm{Y}_{\mathrm{E}} ; \mathrm{A}_{\mathrm{Q}^{\prime}} / \mathrm{A}_{\mathrm{T}}(\mathrm{T})$ & d & $0.78 \pm 0.19$ & $38.12 \pm 1.50$ & 15 & 1768 \\
\hline \multirow[t]{4}{*}{$\mathrm{B}$} & (1) & $\mathrm{X}_{\mathrm{Q}^{\prime}} / \mathrm{Y}_{\mathrm{T}} ; \mathrm{A}_{\mathrm{Q}^{\prime}} / \mathrm{A}_{\mathrm{T}}\left(\mathrm{Q}^{\prime}\right)$ & c & $1.82 \pm 0.75$ & $42.78 \pm 1.87$ & 13 & 1002 \\
\hline & (2) & $\mathrm{X}_{\mathrm{Q}^{\prime}} / \mathrm{Y}_{\mathrm{L}} ; \mathrm{A}_{\mathrm{Q}^{\prime}} / \mathrm{A}_{\mathrm{L}}\left(\mathrm{Q}^{\prime}\right)$ & $\mathrm{c}$ & $0.13 \pm 0.13$ & $2.80 \pm 0.45$ & 18 & 3264 \\
\hline & (3) & $\mathrm{X}_{\mathrm{L}} / \mathrm{Y}_{\mathrm{T}} ; \mathrm{A}_{\mathrm{Q}^{\prime}} / \mathrm{A}_{\mathrm{L}}(\mathrm{L})$ & $\mathrm{d}$ & $0.07 \pm 0.07$ & $8.38 \pm 2.21$ & 13 & 2110 \\
\hline & (4) & $\mathrm{X}_{\mathrm{T}} / \mathrm{Y}_{\mathrm{L}} ; \mathrm{A}_{\mathrm{Q}^{\prime}} / \mathrm{A}_{\mathrm{T}}(\mathrm{T})$ & d & $0.96 \pm 0.45$ & $39.09 \pm 1.95$ & 12 & 1525 \\
\hline \multirow[t]{4}{*}{$\mathrm{C}$} & (1) & $\mathrm{X}_{\mathrm{Q}^{\prime}} / \mathrm{Y}_{\mathrm{E}} ; \mathrm{A}_{\mathrm{Q}^{\prime}} / \mathrm{A}_{\mathrm{E}}\left(\mathrm{Q}^{\prime}\right)$ & c & $0.19 \pm 0.09$ & $11.33 \pm 1.25$ & 14 & 1942 \\
\hline & $(2)$ & $\mathrm{X}_{\mathrm{Q}^{\prime}} / \mathrm{Y}_{\mathrm{L}} ; \mathrm{A}_{\mathrm{Q}^{\prime}} / \mathrm{A}_{\mathrm{L}}\left(\mathrm{Q}^{\prime}\right)$ & c & $0.13 \pm 0.13$ & $2.80 \pm 0.45$ & 18 & 3264 \\
\hline & (3) & $\mathrm{X}_{\mathrm{L}} / \mathrm{Y}_{\mathrm{E}} ; \mathrm{A}_{\mathrm{Q}^{\prime}} / \mathrm{A}_{\mathrm{L}}(\mathrm{L})$ & d & 0 & $2.25 \pm 0.47$ & 13 & 2076 \\
\hline & (4) & $\mathrm{X}_{\mathrm{E}} / \mathrm{Y}_{\mathrm{L}} ; \mathrm{A}_{\mathrm{Q}^{\prime}} / \mathrm{A}_{\mathrm{E}}(\mathrm{E})$ & $\mathrm{d}$ & $0.15 \pm 0.11$ & $9.34 \pm 1.25$ & 17 & 2568 \\
\hline
\end{tabular}

b

\begin{tabular}{|c|c|c|c|c|c|c|}
\hline & $(1)-(2)$ & $(1)-(3)$ & $(1)-(4)$ & $(2)-(3)$ & $(2)-(4)$ & (3)-(4) \\
\hline \multicolumn{7}{|l|}{ A } \\
\hline \multirow[t]{2}{*}{$2-\mathrm{chr}$} & $>$ & $>$ & $>$ & $<$ & $<$ & $<$ \\
\hline & $0.05>p>0.01$ & $0.1>p>0.05$ & $0.5>p>0.4$ & $0.8>p>0.7$ & $0.05>p>0.01$ & $0.1>p>0.05$ \\
\hline \multirow[t]{2}{*}{ 3-chr. } & $>$ & $>$ & $>$ & $<$ & $<$ & $<$ \\
\hline & $0.05>p>0.01$ & $0.01>p$ & $0.05>p>0.01$ & $0.01>p$ & $0.01>p$ & $0.01>p$ \\
\hline \multicolumn{7}{|l|}{ B } \\
\hline \multirow[t]{2}{*}{$2-\mathrm{chr}$} & $>$ & $>$ & $>$ & $>$ & $<$ & $<$ \\
\hline & $0.01>p$ & $0.01>p$ & $0.4>p>0.3$ & $1.0>p>0.9$ & $0.05>p>0.01$ & $0.05>p>0.01$ \\
\hline \multirow[t]{2}{*}{ 3-chr. } & $>$ & $>$ & $>$ & $<$ & $<$ & $<$ \\
\hline & $0.01>p$ & $0.01>p$ & $0.2>p>0.1$ & $0.05>p>0.01$ & $0.01>p$ & $0.01>p$ \\
\hline \multicolumn{7}{|l|}{$\mathrm{C}$} \\
\hline \multirow[t]{2}{*}{$2-\mathrm{chr}$} & $>$ & $>$ & $>$ & $>$ & $<$ & $<$ \\
\hline & $0.3>p>0.2$ & $0.05>p>0.01$ & $0.5>p>0.4$ & $0.5>p>0.4$ & $0.8>p>0.7$ & $0.3>p>0.2$ \\
\hline \multirow[t]{2}{*}{ 3-chr. } & $>$ & $>$ & $>$ & $>$ & $<$ & $<$ \\
\hline & $0.01>p$ & $0.05>p>0.01$ & $0.3>p>0.2$ & $0.5>p>0.4$ & $0.01>p$ & $0.01>p$ \\
\hline
\end{tabular}

Experiment II.

To further characterize the factors in the autosomes (A) and the Y-chromosome contributing to the male crossing-over, two strains of cosmopolitan forms, $\mathrm{E}$ and $\mathrm{L}$, and one strain of dark form $\mathrm{T}$ were used as mentioned above. Combining $\mathrm{Y}$ and $\mathrm{A}$ from the three strains in all ways, nine experimental classes were obtained. For convenience in discussing the results, three groups of four suitable classes, similar to the 
set in Experiment I, were arranged as seen in Table 2a. Within each set, the four classes of males also varied with respect to the origin of their X-chromosome and cytoplasm.

It has been observed that the recombination values of $X_{Q^{\prime}} / Y_{T} ; A_{Q^{\prime}} / A_{T}$ class are highest, $X_{Q^{\prime}} / Y_{E} ; A_{Q^{\prime}} / A_{E}$ and $X_{Q^{\prime}} / Y_{L} ; A_{Q^{\prime}} / A_{L}$ standing in order, confirming again the previous result (Moriwaki et al. 1978). Following the discussion process in Experiment I, comparisons were made between two classes in each group as summarized in Table $2 b$.

Comparing recombination values between two classes in each of the A and B groups, (1) and (3) as well as (2) and (4), it can be concluded that some factors in the autosomes from the $T$ strain $\left(A_{T}\right)$ more effectively enhance male crossing-over than those from $E$ or $L$ strain $\left(A_{E}\right.$ or $\left.A_{L}\right)$. In the $C$ group, that the autosomes from the $E$ strain $\left(A_{E}\right)$ enhance male crossing-over more than those from the $L$ strain $\left(A_{L}\right)$ can be inferred, as shown in the classes (1) and (3) (Table 2).

The existence of some active factors for male crossing-over in $\mathrm{Y}$-chromosome can be suggested here, as for in Experiment $I$, based on the comparisons that $Y_{T}>Y_{E}$ and $Y_{T}>Y_{L}$ in both the $A$ and $B$ groups, in terms of the effectiveness on male crossingover. While, in the $C$ group, no such differences between $Y_{E}$ and $Y_{L}$ can be ascertained. This may mean that the Y-chromosome's contribution is relatively less than the A's, in general, and would not be appreciable in case the frequency difference of male recombination is as small as that seen between $\mathrm{E}$ and $\mathrm{L}$.

\section{DISCUSSION}

Equality of the complementary genotypes in crossovers was observed in most of the families through Experiments I and II, indicating the meiotic origin of male crossing-over in this species, in accordance with the previous report (Moriwaki et al. 1970).

According to the results in Experiments I and II, it can be concluded that the major factors on male crossing-over exist autosomes, accompanying some factors in the Y-chromosome, and that those factors originated from the Tonga strain are usually powerful. Moreover, some interaction between the Y-chromosome and autosomes for male recombination is inferred, showing the higher frequency in males of "hybrid genome".

In addition to the effect of "hybrid genome" some interaction of cytoplasm with it was suggested, making a comparison between the fourth class of Experiment I and the fourth class of Experiment IIA and B, where the marker genes, $D l$ and $b w$, on the second chromosome and autosomes of the Tonga strain were included commonly. Significant differences in male recombination values in the interval between $D l$ and $b w$ have been found as follows:

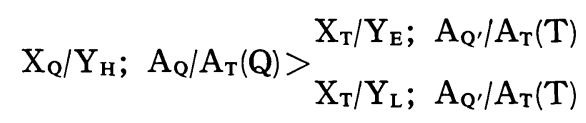

where the symbol in parenthesis means the origin of cytoplasm. The main difference 
between the classes of Experiments I and II is the origin of cytoplasm and X-chromosome, which are derived from $Q$ in the former while in the latter from $T$. It thus appears, taking into account that the effect of the $Y_{H}$ was close to that of $Y_{E}$ or $Y_{L}$, on recombination between $D l$ and $b w$, that "hybrid genome" might interact with cytoplasm and/or X-chromosome to enhance male crossing-over, where $\mathrm{Y}$, autosomes, and cytoplam (and/or X-chromosome) originated from three different strains.

In this regard, it is of interest that there exist cytoplasm-chromosome interaction, when each cytoplasm, sex chromosomes and autosomes derived from different forms, which have been isolated geographically. However, it is difficult to discuss the relationship between cytoplasmic effect observed in the present experiment and the extrachromosomal suppressor reported by Hinton (1974), because the nature of cytoplasmic factors indicated in the present experiment have not yet been investigated. Hinton (1974) reported that $F_{1}$ males produced by reciprocal crosses between two stocks of $D$. ananassae have shown different recombination frequencies. According to him, genetic analysis of this difference revealed an extrachromosomal suppressor of male crossingover, maternally transmitted and dependent upon a specific third chromosome for its maintenance.

In a previous report (Moriwaki et al. 1970), the heterozygous males derived from the cross between marker females and wild type (Tonga inbred lines) males have shown almost always significantly higher recombination values than the reciprocal $F_{1}$ males, which suggested some effect of the sex chromosomes or cytoplasm on male crossingover. The effectiveness of the Y-chromosome from the Tonga strain has been recognized in the present experiment, and the indicated role of Y-chromosome for the reciprocal cross difference can be applied without inconsistency.

In D. melanogaster, Kidwell and Kidwell (1975) obtained the reciprocal effect on male recombination, and $F_{1}$ fertility in both males and females. Later, the term "hybrid dysgenesis" has been coined for the syndrome of events associated with male recombination (Kidwell et al. 1977).

In D. ananassae, some aspects of the characteristic syndrome of "hybrid dysgenesis" have also been found (in preparation). However, the direction of reciprocal differences in male recombination frequencies was variable in the case where cosmopolitan strains were crossed with marker strains to make $\mathrm{F}_{1}$ males to be examined (Moriwaki et al. 1970).

The factors changing male crossing-over, which were ascertained to exist on $\mathrm{Y}$ chromosome and autosomes, have been implied to be dominant judging from the data obtained in the experiment. Formerly, Kikkawa (1938) and Moriwaki (1938, 1940) located a dominant gene or genes enhancing crossing-over in males on the third and the second chromosomes of D. ananassae. In 1970 Hinton reported that the spontaneous occurrence of crossing-over in males was shown to depend on a dominant enhancer $(E)$ in the third chromosome and on recessive alleles of a dominant suppressor $(S)$ in the second chromosome, also noting evidence suggestive of additional modifiers. The relationships between those dominant enhancing factors, $E$ (Hinton 1970), En (Kikkawa 1938), and $E n-I I$ (Moriwaki 1940), and the newly obtained dominant ones in the present experiment, have not been determined. 
The possibility of effects of the 4 th chromosome on male crossing-over, which was not examined in the present experiment, can not be ignored, since it has been known to be heterochromatic and partly homologous with the Y-chromosome (Kaufmann 1937; Kikkawa 1938).

\section{ACKNOWLEDGMENT}

We wish to express our sincerest appreciation to Dr. C. W. Hinton for reading the manuscript and valuable suggestions.

\section{LITERATURE CITED}

Futch, D. G., 1966 A study of speciation in South Pacific populations of Drosophila ananassae. Univ. Texas Publ. 6615: 79-120.

Hinton, C. W., 1970 Identification of two loci controlling crossing over in males of Drosophila ananassae. Genetics 66: 663-676.

Hinton, C. W., 1974 An extrachromosomal suppressor of male crossing over in Drosophila ananassae. In "Mechanisms in Recombination". (R. F. Grell, ed.) pp. 391-397. Plenum, New York.

Kaufmann, B. P., 1937 Morphology of the chromosomes of Drosophila ananassae. Cytologia (Tokyo) Fujii Jubilee Vol.: 1043-1055.

Kidwell, M. G., and J. F. Kidwell, 1975 Cytoplasm-chromosome interaction in Drosophila melanogaster. Nature 253: 755-756.

Kidwell, M. G., J. F. Kidwell, and J. A. Sved, 1977 Hybrid dysgenesis in Drosophila melanogaster A syndrome of aberrant traits including mutation, sterility and male recombination. Genetics 86: 813-833.

Kikkawa, H., 1938 Studies on the genetics and cytology of Drosophila ananassae. Genetica (The Hague) 20: 458-516.

Moriwaki, D., 1938 Enhanced crossing over in the second chromosome of Drosophila ananassae (preliminary note). Japan. J. Genetics 14: 283-284.

Moriwaki, D., 1940 Enhanced crossing over in the second chromosome of Drosophila ananassae. Japan. J. Genetics 16: 37-48.

Moriwaki, D., and Y. N. Tobari, 1973 Spontaneous male crossing-over in Drosophila ananassae from Southeast Asian populations. Japan. J. Genetics 48: 167-173.

Moriwaki, D., and Y. N. Tobari, 1975 Drosophila ananassae. In "Handbook of Genetics" (R. C. King, ed.) Vol. 3, pp. 513-535. Plenum, New York.

Moriwaki, D., Y. N. Tobari, and M. Matsuda, 1978 Genetic factors controlling male crossing-over in Drosophila ananassae. (Abstract) Japan. J. Genetics 53: 438.

Moriwaki, D., Y. N. Tobari, and Y. Oguma, 1970 Spontaneous crossing-over in the male of Drosophila ananassae. Japan. J. Genetics 45: 411-420. 